\title{
Effects of nutrient availability and light intensity on the sterol content of Saccharina latissima (Laminariales, Phaeophyceae)
}

\author{
Dylan L. C. de Jong ${ }^{1}$ (D) $\cdot$ Klaas R. Timmermans ${ }^{1,2} \cdot$ José M. de Winter ${ }^{1} \cdot$ Goverdina C. H. Derksen $^{1,2}$ (D)
}

Received: 28 September 2020 / Revised and accepted: 16 December 2020 / Published online: 7 January 2021

(C) The Author(s) 2021

\begin{abstract}
Seaweed phytosterols are associated with potential health benefits, affording them and the seaweeds that produce them commercial interest. However, little is known about how their production is affected by the cultivation environment, limiting the efficiency with which these compounds can be exploited. Therefore, we performed a pilot study on the effect of nutrient availability and light stress on the sterol content of Saccharina latissima, a rapid growing brown alga of increasing interest in western mariculture. Individuals of $S$. latissima were subjected to a nutrient-replete and nutrient-depleted regime for 5 weeks, followed by the introduction of light-limited and light-saturated conditions in the sixth week; sampling occurred each week. No significant inter-treatment differences were found in the sterol content in week 1-5. However, significant intra-treatment differences were found in weeks 3-5 regardless of nutrient treatment, wherein the fucosterol, 24-methylenecholesterol, and squalene contents of both treatment groups were found to correlate inversely with photosynthetic performance. Factorial treatment of differential nutrient availability and light stress resulted in marked differences between the sterol content of all groups in week 6 . Here, squalene and cycloartenol increased in concentration with increasing irradiance regardless of nutrient treatment. Concentrations of all other sterolic components increased with increasing irradiance and low nutrient conditions while decreasing or remaining unchanged with increasing irradiance and high nutrient conditions. Our data shows that within our cultivation conditions and time frame, the sterol content of S. latissima is unaffected by nutrient availability alone but changes with combined alterations in irradiance and nutrient availability.
\end{abstract}

Keywords Seaweed $\cdot$ Phaeophyceae $\cdot$ Phytosterols $\cdot$ Differential cultivation $\cdot$ Fucosterol $\cdot$ Stress

\section{Introduction}

Seaweeds are a group of photosynthetic marine organisms that are increasingly exploited as sources of food, feed, thirdgeneration biofuels, and high-value biochemicals (Camia et al. 2018). They are characterized by fast growth rates, are capable of fixing anthropogenic $\mathrm{CO}_{2}$, grow on inorganic nutrients, and do not compete for arable land (van der Molen et al. 2018). The global production of seaweed reached 29 million tons (US\$ 4.8 billion) in 2015 (FAO 2018).

Dylan L. C. de Jong

dlc.de.jong@hz.nl

1 Research Group Marine Biobased Specialties, HZ University of Applied Sciences, P.O. Box 364, 4380

AJ Vlissingen, The Netherlands

2 Department of Estuarine and Delta Systems, NIOZ Royal Netherlands Institute for Sea Research, P.O. Box 140, 4401 Nt Yerseke, The Netherlands
Comparatively, the production rate of the largest commercial seaweed cultivator in the Netherlands reached approximately $10 \mathrm{t}$ per year in 2017 (Kamsma 2017). The focal species of commercial mariculture in Europe and the Netherlands is Saccharina latissima (van der Molen et al. 2018). While this species has received considerable economic attention for its feed and pharmaceutical uses (Breton et al. 2018) and has been touted as a superfood (Parodi et al. 2018), its largescale cultivation in promising areas such as the North Sea is not economically feasible (van den Burg et al. 2016). An economically feasible seaweed value chain can be realized not by simply increasing production volumes, but instead by identifying and utilizing valuable by-products (van den Burg et al. 2019); the same holds true for North Sea cultivation (van den Burg et al. 2016). One group of currently underutilized seaweed natural products is the phytosterols, which are known for their structural variety and bioactive properties.

Phytosterols are naturally occurring triterpenes that structurally and functionally resemble cholesterol (Hartmann 1998). Like all sterols, phytosterols are essential membrane 
components, regulating membrane fluidity and permeability in a manner that is essential for eukaryotic life (Carlson et al. 1980; Volkman 2003). Contrary to the monosterolic Mammalia and Fungi, plants and algae can produce characteristically complex mixtures of phytosterols (Dufourc 2008), of which over 260 individual compounds have been reported in terrestrial plants alone (Akihisa et al. 1992). Macroalgae are no exception to this sterolic complexity; the unique polyphyletic nature of algal evolution has led to a great diversity in metabolic processes amongst them (Beardall and Raven 2012). Algae are able to synthesize sterols via two isoprenoid biosynthesis pathways, the mevalonate and the methyl-Derythritol 4-phosphate pathways (Lopes et al. 2014), the prevalence of each in a given species depending on its evolutionary origin (Kumari et al. 2013). Either of these pathways results in the production of squalene, which is then cyclized to cycloartenol and subsequently follows a cascade of enzymatic conversions (Goad and Akihisa 1997) to produce the myriad of phytosterols found in marine algae. In brown macroalgae such as S. latissima, this biosynthetic cascade concludes in the methylation of 24-methylenecholesterol to produce fucosterol, the main sterol of brown seaweed (Goad and Goodwin 1969; Goad et al. 1974).

Since Peterson's (1951) original observations on the cholesterol-lowering effects of soybean sterols, reports have been published on Chlorophyceae (green seaweeds) sterols exhibiting anti-inflammatory (Lee et al. 2013) and diabetesmediating (Li et al. 2017) activity, Rhodophyceae (red seaweeds) sterols exhibiting anti-cancer (Ktari et al. 2000; Lin et al. 2010) and antibacterial (Kavita et al. 2014) effects, and Phaeophyceae (brown seaweeds) sterols exhibiting antiadipogenic (Jung et al. 2014), anti-cancer (Sheu and Sung 1991; Ktari and Guyot 1999), anti-tuberculosis (Wächter et al. 2001), and Alzheimer-mediating (Vanmierlo et al. 2015; Bogie et al. 2019) activities, amongst many others. These bioactive sterols are often found in edible seaweeds, an example being fucosterol isolated from the edible brown seaweed Ecklonia stolonifera, which inhibits adipogenesis in 3T3-L1 adipocytes and may thus be useful in the treatment of obesity (Lee et al. 2017). Moreover, physiologically relevant concentrations of these phytosterols can sometimes be reached through dietary supplementation, as is the case with Alzheimer-mediating 24(S)-Saringosterol isolated from Sargassum fusiforme (Bogie et al. 2019). This imbeds great value into these compounds as possible pharmaceuticals or functional foods, and subsequentially into seaweeds themselves as their producers.

Harvesting the full potential of these compounds however not only requires probing into their bioactivity but also into what governs their production. Abiotic cultivation parameters such as temperature, light quality and intensity, nutrient availability, and salinity are all known to affect the lipid composition of both micro- and macroalgae (Guschina and Harwood
2009; Juneja et al. 2013). For Saccharina latissima, biomass quality and quantity are most affected by light and nutrient availability (Boderskov et al. 2016; Lubsch and Timmermans 2019). However, despite the increasing interest in seaweed phytosterols, very little is known about how their production is affected by the cultivation environment.

Previous research on the effect of nutrient and light availability on algal sterol production mostly concerns microalgae. In both freshwater and marine microalgae, phosphorus limitation is generally associated with a decrease in the total sterol content. This is thought to proceed either directly through downregulation of sterol-producing enzymes or indirectly through a reduced production of phospholipid bilayers into which sterols can be incorporated (Piepho et al. 2010, 2012). The effect of nitrogen availability on algal sterols appears to be more species specific. The green microalga Botryococcus braunii exhibits increases in sterol content under nitrogen limitation (Zhila et al. 2005), while the reverse response has been observed for Nannochloropsis oceanica (Lu et al. 2014). In this latter species, nitrogen limitation led to a reduction of sterol biosynthesis caused by downregulation of methyl-Derythritol 4-phosphate pathway genes. Conversely, some species of microalgae maintain the same sterol content regardless of nitrogen concentration (Krauss and McAleer 1953; Gordillo et al. 1998). Light quality and quantity can also affect microalgal sterol content. When the microalga $N$. oceanica experiences high light stress, it undergoes rapid downregulation of genes involved in sterol biosynthesis and experiences impaired photosynthesis. Targeted inhibition of sterol biosynthesis in the same species resulted in severely deviating chloroplast structure and reduced photosynthesis rates, implicating sterols as necessary components of the chloroplast membrane (Lu et al. 2014). The involvement of sterols in the chloroplast is also exemplified in the microalga Euglena gracilis, which does not produce chloroplasts when grown in the absence of light. Under these conditions, the microalgae accumulate sterol precursors and produce significantly less free sterols and increased amounts of esterified sterols, concomitant with a shift from $\Delta^{7}$-sterols to $\Delta^{5}$-sterols (Brandt et al. 1970; Anding et al. 1971). This suggests that specific sterol species within an algae may be enriched in specific lipid membranes such as the chloroplast, as is the case in some higher plants (Brandt and Benveniste 1972).

How the abovementioned responses translate to brown macroalgae remains elusive as, to the best of our knowledge, only one publication deals with the effect of light and nutrients on brown algal sterols. When Cronin and Hay (1996) investigated the individual and interactive effects of light intensity and nutrient availability on the total sterol content of the brown algae Dictyota ciliolata and Sargassum filependula, they found that neither factor individually significantly affected the sterol content of either species. When both factors were applied simultaneously and under field conditions however, a 
significantly higher sterol content was observed in $D$. ciliolata grown under low light conditions. While the mechanism behind this observation was not explored further, the higher sterol content under low light conditions suggests a response similar to the one described by $\mathrm{Lu}$ et al. (2014). Here, we report experimental results of a pilot study on the effects of nutrient availability as well as the factorial effects of nutrient availability and light intensity on the phytosterol content of S. latissima. The nature of this pilot study dictates that the individuals of $S$. latissima used can only be considered independent samples of our specific culture conditions. We therefore adopt the approach of Cottenie and De Meester (2003), limiting the scope of our interpretations to the experimental conditions used. While our data are subjected to the appropriate inferential statistics, we have refrained from extrapolating results of this study to larger populations.

\section{Materials and methods}

\section{Chemicals and reagents}

All chemicals and reagents were of analytical grade unless mentioned otherwise. Methanol and dichloromethane were from Avantor (Poland). Ethyl acetate was from Acros Organics (Belgium). Potassium hydroxide (85\%) and anhydrous sodium sulfate were obtained from Merck (Germany). $\mathrm{N}, \mathrm{O}-\mathrm{Bis}$ (trimethylsilyl)trifluoroacetamide with $1 \%$ trimethylchlorosilane (BSTFA:TMCS, 99:1, v/v), anhydrous pyridine, squalene ( $\geq 98 \%$ ), cholesterol $(99 \%)$, and cycloartenol $(\geq 90 \%)$ were obtained from Sigma-Aldrich (Germany). Fucosterol $(\geq 98 \%)$ and desmosterol ( $\geq 98 \%)$ were from Cayman Chemical (USA), epicoprostanol (99.8\%) from United States Pharmacopeia (Rockville, USA), and 24-methylenecholesterol (>99\%) was from Avanti Polar Lipids (USA).

\section{Nutrient variable cultivation}

In this first experiment, the effect of nutrient availability on the sterol content of Saccharina latissima was investigated. Juvenile sporophytes of $S$. latissima were obtained from commercial cultivator Zeewaar (51 $\left.35^{\circ} 55.7^{\prime \prime} \mathrm{N} 3^{\circ} 41^{\prime} 04.0^{\prime \prime} \mathrm{E}\right)$ and grown for 1 year in outdoor cultivation tanks at Royal Netherlands Institute for Sea Research (NIOZ) Yerseke (51 ${ }^{\circ}$ $29^{\prime} 22.0^{\prime \prime} \mathrm{N} 4^{\circ} 03^{\prime} 25.5^{\prime \prime}$ E). The nutrient-variable experiment consisted of two treatment groups, a nutrient-high (HN) and a nutrient-low (LN) group. Each group consisted of 49 individuals with an average length of $35.9 \pm 7.4 \mathrm{~cm}$. Cultivation was achieved outdoors in two 1500-L cultivation tanks, allowing both groups to be equally exposed to ambient temperatures and sunlight (Fig. 1). Temperature was logged in 30-min intervals using a HOBO Pendant logger (MX2202, Onset Computer Corporation, USA) while light intensity was logged in 5-min intervals using a LI-1400 light logger equipped with an LI-192SA flat sensor (LI-COR, USA), both placed $20 \mathrm{~cm}$ below the water surface (data shown in Fig. S1). Aeration was provided to keep individuals of $S$. latissima, which were allowed to freely tumble inside the cultivation tanks, in constant motion. Cultivation water in the $\mathrm{HN}$ tank was refreshed weekly with filtered $( \pm 0.50 \mu \mathrm{m})$ seawater pumped directly from the Oosterschelde over the course of $3 \mathrm{~h}$, to which approximately $51 \mu \mathrm{M} \mathrm{NH}_{4}, 148 \mu \mathrm{M} \mathrm{NO}_{3}$, and $25 \mu \mathrm{M} \mathrm{PO}_{4}$ was added every time the tank was completely refreshed. These quantities were determined to saturate the uptake kinetics of 49 individuals of S. latissima (Lubsch and Timmermans 2019), thus ensuring that the nutrient availability of this group was higher than the total nutrient uptake throughout the entire experiment. Nutrient-poor cultivation water for the LN group was obtained by providing the $\mathrm{LN}$ tank with seawater from the Oosterschelde at the start of the cultivation period and not refreshing it thereafter, resulting in a steady decrease of available nutrients over the course of the experiment until uptake kinetics were no longer saturated. Nutrient concentrations
Fig. 1 Schematic overview of the nutrient variable (weeks $1-5$, outside cultivation tanks) and nutrient and light factorial (week 6, climate controlled) cultivation experiments. $\mathrm{HN}$ and $\mathrm{LN}$ denote high nutrient and low nutrient respectively; HL and LL denote high light and low light respectively

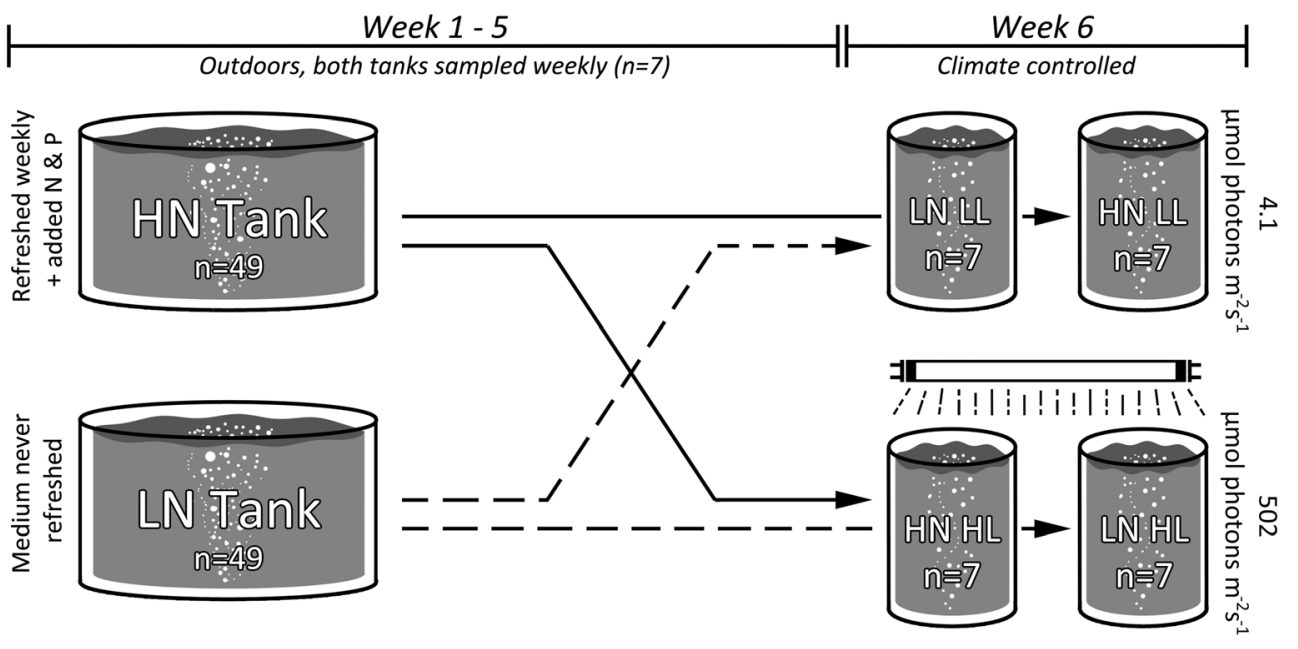


$\left(\mathrm{NH}_{4}, \mathrm{NO}_{2}, \mathrm{NO}_{3}, \mathrm{PO}_{4}\right.$ and combined $\mathrm{Si}$ and $\left.\mathrm{SiO}_{2}\right)$ are presented in Fig. 2 (data in Table S1) and were measured in triplicate using a QuAAtro39 Continuous Segmented Flow Analyzer (SEAL Analytical, Germany). Nutrient-variable cultivation proceeded for 5 weeks from 19 November 2018 until 21 December 2018, during which 7 individuals were randomly sampled weekly from each cultivation tank.

\section{Light and nutrient variable cultivation}

In this second experiment, the simultaneous effect of nutrient availability and light intensity on the sterol content of $S$. latissima was investigated. After the 5th week of nutrient variable cultivation, the remaining 28 individuals (14 from each 1500-L tank) of $S$. latissima were transferred to a lightvariable cultivation setup. Individuals were suspended to complete submersion from their stipe in 50-L cultivation tanks, located in a climate-controlled room set to $5{ }^{\circ} \mathrm{C}$ to match the average outdoor temperature $\left(4.7^{\circ} \mathrm{C}\right.$ in the prior week). Four tanks were present in total, two of which each contained $7 \mathrm{HN}$ individuals and two of which each contained $7 \mathrm{LN}$ individuals. All tanks were provided with their respective cultivation medium (i.e., $\mathrm{LN}$ and $\mathrm{HN}$ tanks were respectively provided with $\mathrm{LN}$ and $\mathrm{HN}$ medium from the outdoors cultivation tank). One of each LN and $\mathrm{HN}$ tanks was exposed to an irradiance of $4.12 \pm 0.14 \mu \mathrm{mol}$ photons $\mathrm{m}^{-2} \mathrm{~s}^{-1}$ (cumulative PAR of

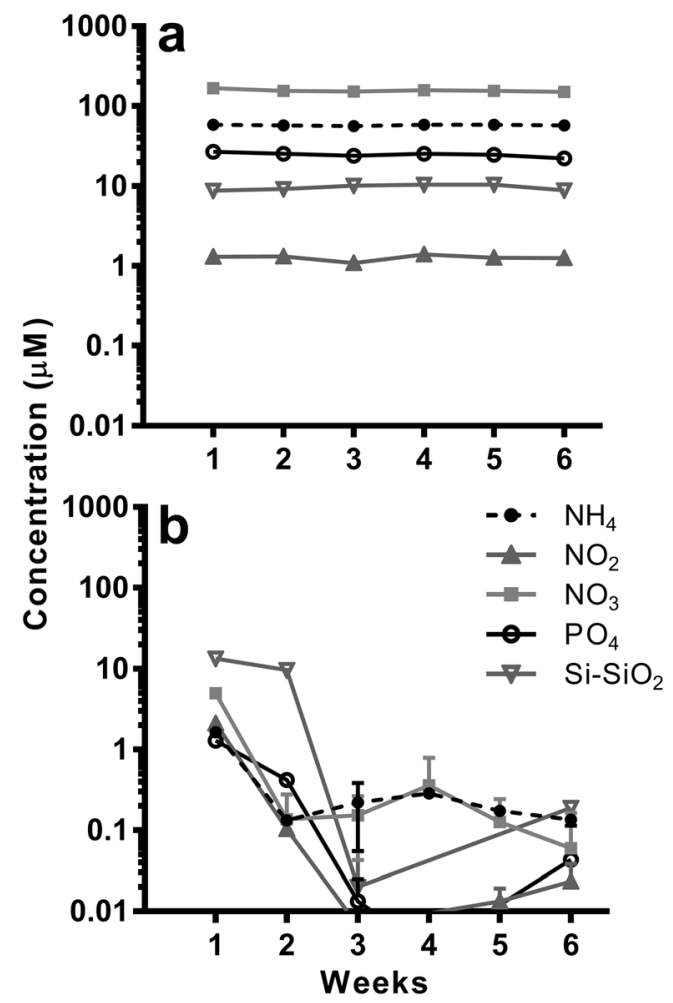

Fig. 2 Mean nutrient (mean \pm S.D., $n=3$ ) concentrations in the highnutrient (a) and low-nutrient (b) tanks during the nutrient variable (week 1-5) and nutrient/light factorial (week 6) experiments
0.2 mol photons $\mathrm{m}^{-2} \mathrm{day}^{-1}$ ), the other tank of each group being exposed to an irradiance of $502.4 \pm 3.1 \mu \mathrm{mol}$ photons $\mathrm{m}^{-2} \mathrm{~s}^{-1}$ (cumulative PAR of $21.7 \mathrm{~mol}$ photons $\mathrm{m}^{-2}$ day $^{-1}$ ); all tanks followed a $12-\mathrm{h} / 12-\mathrm{h}$ diurnal rhythm. Irradiances were chosen to respectively precede the light-limiting and exceed the light-saturating irradiance for S. latissima (Davison et al. 1991). Light was provided by cool white fluorescent lamps (TL-D $36 \mathrm{~W} / 840$, Philips, the Netherlands) and measured using a LI-250 light meter (LI-COR, USA) equipped with a US-SQS/L spherical sensor (Heinz Walz GmbH, Germany). Measurements were taken at two locations, just below the water surface and at the bottom of the cultivation tanks. All remaining individuals were harvested 1 week later on the 2 nd and 3rd of January, 2019.

\section{Sampling and photosynthetic measurements}

As a non-destructive additional means to gain insight into the possible stress response of S. latissima, individuals were subjected to pulse amplitude modulation (PAM) fluorometric measurements of photosynthesis. Sampling consisted of transferring individuals of S. latissima, 2 or 3 at a time, to a lowlight laboratory environment in a container filled with their respective cultivation medium. Following $10 \mathrm{~min}$ of dark acclimation, chlorophyll $a$ fluorescence was measured by means of PAM fluorometry using an IMAG-MIN/R fluorometer attached to an IMAG-CG control unit (Heinz Walz GmbH, Germany). Saccharina latissima individuals were incrementally exposed to 14 irradiance levels ranging from 0 to $1100 \mu \mathrm{mol}$ photons $\mathrm{m}^{-2} \mathrm{~s}^{-1}$ at 30 -s intervals, from which the maximum photosynthetic rate $\left(P_{\max }\right)$, light utilization efficiency $(\alpha)$, and saturating irradiance $\left(E_{k}\right)$ values were directly modeled using Webb et al. (1974). Following this, individuals were rinsed in cultivation medium rather than freshwater to prevent osmotically induced metabolic changes (Davison and Reed 1985; Francavilla et al. 2010). Visible epiphytes were removed, and thalli were gently wiped with cloth to remove bacterial films (Conolly and Drew 1985), before gently blotting them dry with paper towels. Individuals were subsequently sectioned into $5 \mathrm{~cm}$ longitudinal segments starting from the stipe, the meristem section of which was used for subsequent analyses for its high concentration of sterols (Black 1954) and high rate of metabolic differentiation (Schmid and Stengel 2015). Samples were lyophilized (Beta 1-8 LD, Christ, Germany) for $48 \mathrm{~h}$ in the dark, after which they were homogenized using an MM301 ball mill (Retsch $\mathrm{GmbH}$, Germany) for $30 \mathrm{~s}$ at $30 \mathrm{~Hz}$ and stored at $-80{ }^{\circ} \mathrm{C}$ until further use.

\section{Saponification and extraction of sterols}

Of each sample, $\pm 50 \mathrm{mg}$ was added to a round-bottom flask, already containing $100 \mu \mathrm{g}$ of epicoprostanol (added in 
solution, dried under $\mathrm{N}_{2}$ ). The sample was then saponified in 5-mL ethanolic potassium hydroxide ( $1 \mathrm{M})$ under reflux and constant stirring for $1 \mathrm{~h}$. Allowing it to subsequently cool down, the contents were transferred to a centrifuge tube to which $2.5 \mathrm{~mL}$ of dichloromethane and $2 \mathrm{~mL}$ of $\mathrm{H}_{2} \mathrm{O}$ were added, resulting in a final mixture of methanol/ dichloromethane: $\mathrm{H}_{2} \mathrm{O}$ (2:1:0.8). This mixture was vigorously stirred for $10 \mathrm{~min}$, followed by the addition of $2.5 \mathrm{~mL}$ of dichloromethane and $2.5 \mathrm{~mL}$ of $\mathrm{H}_{2} \mathrm{O}$ and subsequent centrifugation for $3 \mathrm{~min}$ at $3000 \mathrm{rpm}$. The dichloromethane layer was retrieved, and the remaining mixture was extracted two more times with dichloromethane, all of which was combined and dried under $\mathrm{N}_{2}$ to yield an orange-brown extract. This was subsequently reconstituted in a small volume of dichloromethane, dried over anhydrous sodium sulfate, and stored under $\mathrm{N}_{2}$ at $-80^{\circ} \mathrm{C}$ awaiting analysis.

\section{Derivatization and GC-MS analysis of sterols}

Silylation was achieved by adding $50 \mu \mathrm{L}$ of pyridine and $50 \mu \mathrm{L}$ of BSTFA:TMCS $(99: 1, \mathrm{v} / \mathrm{v})$ to the extract, after which it was gently homogenized and heated to $70{ }^{\circ} \mathrm{C}$ for $30 \mathrm{~min}$. Then, the extract was allowed to cool to room temperature after which $200 \mu \mathrm{L}$ of ethyl acetate was added. One microliters of the silylated extract was then injected in splitless mode onto a Finnigan TraceGC Ultra gas chromatograph (GC) equipped with a Trace DSQ mass spectrometry (MS) detector (Thermo Fisher Scientific, USA). Separation was achieved over a Restek RTX-5Sil MS column $(30 \mathrm{~m} \times 0.25 \mathrm{~mm} \times$ $0.25 \mu \mathrm{m}$ ) using hydrogen as a carrier gas at $1.2 \mathrm{~mL} \mathrm{~min}^{-1}$ and the following oven program: initial temperature of $55{ }^{\circ} \mathrm{C}$ held for $80 \mathrm{~s}$, followed by a ramp to $235{ }^{\circ} \mathrm{C}$ at $25{ }^{\circ} \mathrm{C} \mathrm{min}{ }^{-1}$, held for $8 \mathrm{~min}$. This was followed by a final ramp to $290{ }^{\circ} \mathrm{C}$ at $4{ }^{\circ} \mathrm{C} \mathrm{min}{ }^{-1}$, for a final runtime of $30 \mathrm{~min}$. The injector was set to $290{ }^{\circ} \mathrm{C}$, with a purge time of $80 \mathrm{~s}$. Detection was achieved in selected-ion-monitoring (SIM) mode, wherein the abundance of preselected quantifier and qualifier ions (see Table 1) was recorded rather than the entire mass spectrum. For each analyte, a quantifier ion was used for quantification, and the relative abundance of two qualifier ions was used to confirm the presence of said analyte. Electron Impact source was set to $70 \mathrm{eV}$ and $250{ }^{\circ} \mathrm{C}$; the transfer line was set to $330^{\circ} \mathrm{C}$. All components were identified based on comparisons of their retention times and mass spectra with authentic reference standards as well as published mass spectra (Goad and Akihisa 1997). Quantification was achieved by fitting the detector response of each analyte to a 12-point calibration curve of its respective standard. Results were normalized to the internal standard and starting weight of the sample.

\section{Statistical analyses}

All data were processed and analyzed in Microsoft Excel 2016 (Microsoft Ltd., USA) using the Real Statistics Resource Pack (Zaiontz 2019). In all analyses, $P<0.05$ was considered significant. For the first experiment (week 1-5), the null hypothesis " $\mathrm{H}_{0}=$ No statistically significant difference in the mean sterol content of $S$. latissima between the high and low nutrient treatments" was tested per week by means of two-tailed, unpaired $t$ tests $(n=7)$. The longitudinal effects of the two treatments over the 5 weeks were assessed per treatment by means of a repeated-measures ANOVA with GeisserGreenhouse correction $(\varepsilon<0.75$ in all cases) per treatment $(n=7)$, operating under the null hypothesis " $\mathrm{H}_{0}=$ No significant difference in the mean sterol content of $S$. latissima between weeks 1 through 5." The above statistics were applied to the inter- and intra-weekly PAM fluorescence measurements. Here, additional listwise exclusion was applied in the repeated-measure ANOVA due to missing data in week 5, limiting the sample size to 6 . The treatment and longitudinal effects on both sterol content and PAM variables were independently assessed by means of multivariate analyses, yielding comparable results (L. Peperzak, personal communication, 22 June 2020). In the second experiment, the null hypothesis " $\mathrm{H}_{0}=$ No statistically significant differences in the mean sterol content of S. latissima between the four treatments was tested by means of a two-way ANOVA and Tukey's HSD post hoc $(n=7)$. The same statistical treatment was again applied to the corresponding PAM fluorescence measurements.
Table 1 Quantifier and qualifier ions used for the sterol analysis of S. latissima lipid fractions (I.S. Internal standard)

\begin{tabular}{lll}
\hline Compound & Quantifier ions $(m / z)$ & Qualifier ions $(m / z)$ \\
\hline Squalene (I) & 69 & 81,136 \\
Cholesterol (II) & 129 & 329,368 \\
Desmosterol (III) & 69 & 129,343 \\
Unknown $\Delta^{5}$-sterol (U.S) & 129 & 296,386 \\
24-Methylenecholesterol (IV) & 129 & 296,386 \\
Fucosterol (V) & 129 & 296,386 \\
Cycloartenol (VI) & 69 & 365,393 \\
Epicoprostanol (I.S.) & 215 & 355,370 \\
\hline
\end{tabular}


Pearson correlation coefficients were used to assess the correlation between any two variables. Linear regressions of the calibration standards were constructed using the least square method. All data are presented as mean \pm standard deviation (S.D.).

\section{Results}

\section{Sterols of Saccharina latissima}

The saponified extract of S. latissima (Fig. 3) contained 2.13\% squalene (I), $0.08 \%$ cholesterol (II), $0.15 \%$ desmosterol (III), 12.3\% 24-methylenecholesterol (IV), $84.7 \%$ fucosterol (V), $0.52 \%$ cycloartenol (VI), and $0.10 \%$ of an unknown $\Delta^{5}$-sterol (U.S) (\% of total sterolic compounds, averaged over the 5-week cultivation experiment of both $\mathrm{LN}$ and $\mathrm{HN}$ groups). The mass spectrum of the unknown $\Delta^{5}$-sterol (U.S), tentatively identified as brassicasterol, can be found in the supplement (Fig. S2).

\section{Effect of nutrient availability on S. latissima: sterols and photosynthesis}

During the 5 weeks of nutrient-variable cultivation, we found no significant differences between the concentration nor the composition of the sterolic components in the $\mathrm{LN}$ and $\mathrm{HN}$ groups in any given week (Fig. 4; Table S2), with the exception of cycloartenol (VI). Thus, with that exception, the null hypothesis that there were no statistically significant differences in the mean sterol content of S. latissima between the high and low nutrient treatments was accepted. For cycloartenol (VI), we observed a significantly higher concentration in the LN group compared with the HN group in week 3 (14.0 vs $10.4 \mathrm{mg} \mathrm{kg}^{-1}$ dry wt., $P=0.0038$ ) and in week 4 (9.61 vs $7.81 \mathrm{mg} \mathrm{kg}^{-1}$ dry wt., $P=0.0048$ ). While no intertreatment differences were observed in sterol content for any given week, the sterolic compounds did exhibit distinct temporal patterns (Fig. 4). Regardless of treatment, differences in concentration over the 5 weeks were proven to be significant for all sterolic components, thus rejecting the null hypothesis that there was no significant difference in the mean sterol content of $S$. latissima between weeks 1 through 5 , with the exception of cholesterol (II) (Table S3). During this period, the total sterol concentration averaged over both groups reached a maximum of $2443 \pm 227 \mathrm{mg} \mathrm{kg}^{-1}$ dry weight in week 3 , representing a $59 \%$ increase compared with the minimum quantity of $1527 \pm 107 \mathrm{mg} \mathrm{kg}^{-1}$ dry weight observed in week 1 . We found strong correlations between the concentration over time of any sterolic compound in one nutrient treatment, and the concentration of the same compound in the other nutrient treatment. These correlations held true for all sterolic compounds (all $R^{2}>0.91, P<0.05$ ), with the exception of cholesterol (II) $\left(R^{2}=0.089, P=0.626\right)$. These temporal patterns did not correlate with the ambient temperature or irradiance, with the exception of the cholesterol (II) content of the HN group and temperature $\left(R^{2}=0.9491, P<0.01\right)$. Significant correlations were found, however, between the photosynthetic variables and squalene (I), desmosterol (III),
Fig. 3 Partial SIM chromatogram of a saponified S. latissima lipid extract, containing squalene (I), cholesterol (II), desmosterol (III), 24-methylenecholesterol (IV), fucosterol (V), cycloartenol (VI) and an unknown $\Delta^{5}$-sterol (U.S). Trace consists of the quantifier ion abundances described in Table 1. "I.S." denotes the internal standard, epicoprostanol. Obtained by means of GC-MS
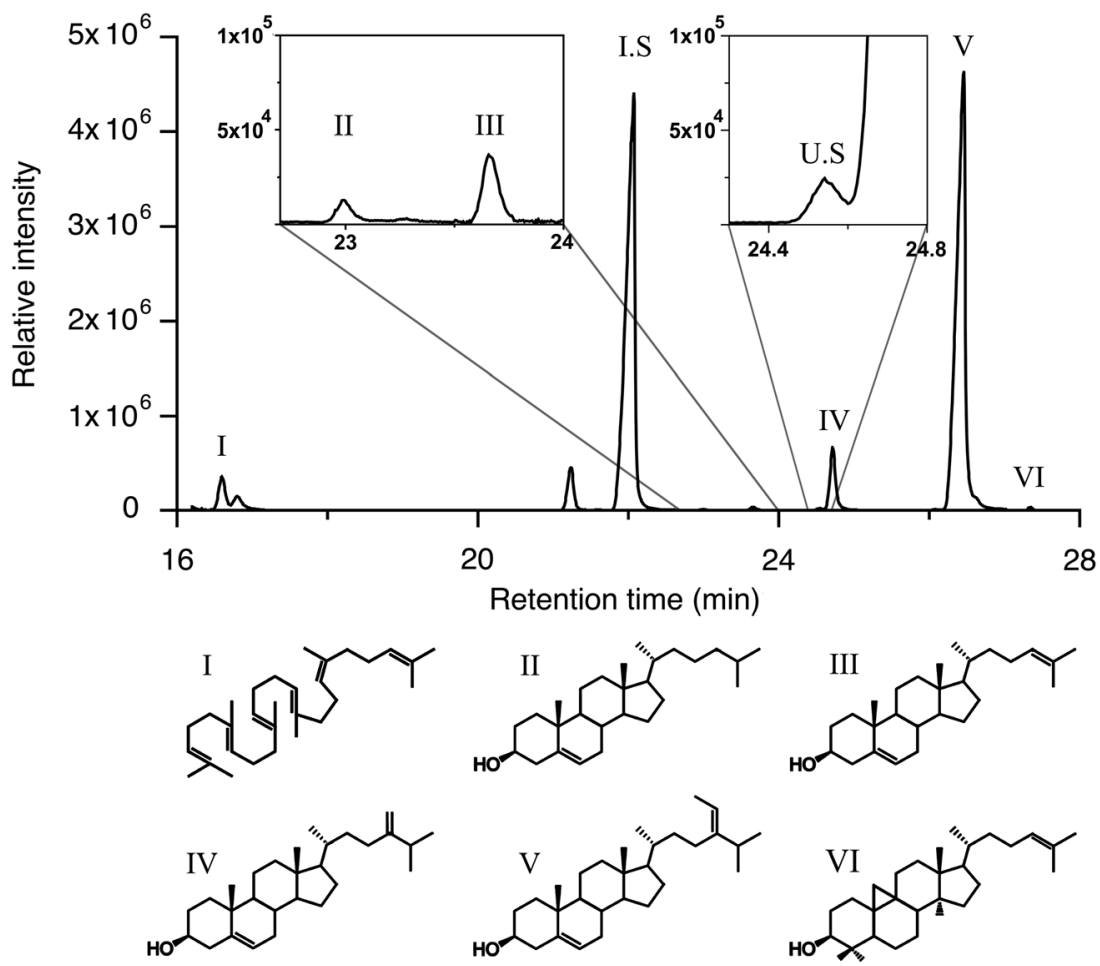
High Nutrients

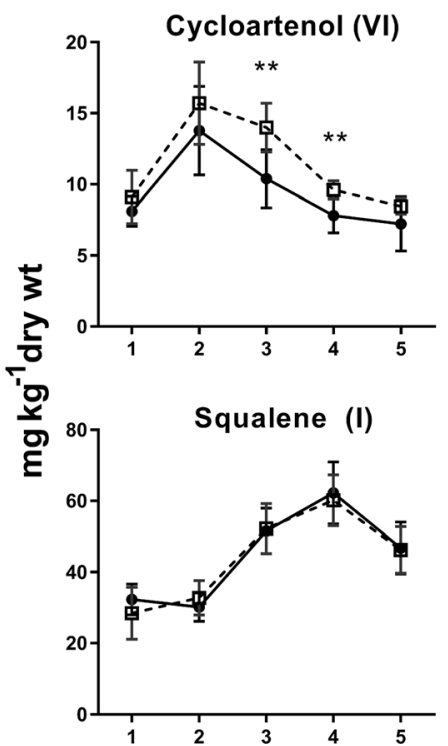

Cholesterol (II)
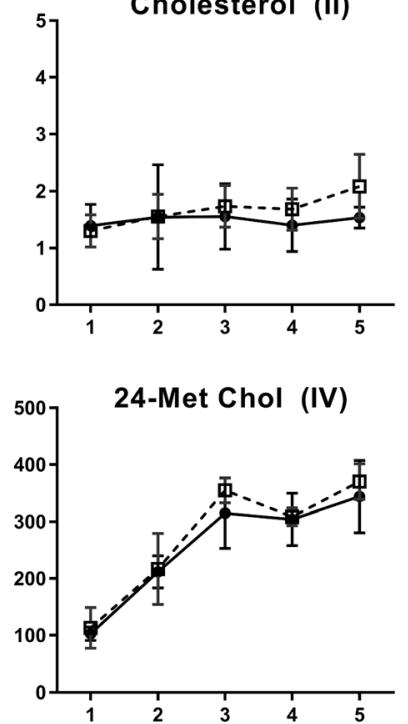

-曰. Low Nutrients
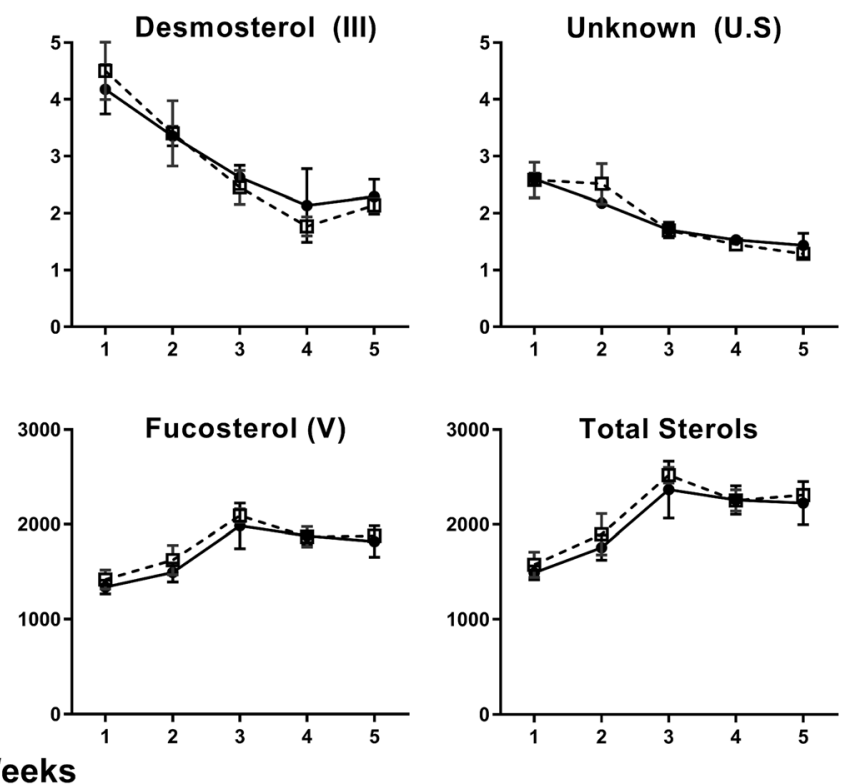

Fig. 4 Concentrations of the sterolic compounds of the high nutrient and low nutrient groups over the course of the nutrient variable cultivation experiment (weeks 1-5, outside cultivation tanks). Data are given as

24-methylenecholesterol (IV), fucosterol (V), and the unknown $\Delta^{5}$-sterol (U.S) (Table 2).

Contrary to the sterol content, the nutrient differentiated cultivation did result in marked differences in photosynthetic performance between the $\mathrm{HN}$ and $\mathrm{LN}$ groups $\left(P_{\max }\right.$ values given in Fig. 5, $\alpha$ and $E_{k}$ provided in Fig. S3). From the third week and thereon after, individuals from the LN tanks mean \pm S.D. $(n=7$, except for cholesterol in LN week 3, where $n=6)$ and accompanied by statistical significance: $* * P<0.01$. Note the differences in scales

exhibited significantly lower $P_{\max }, \alpha$, and $E_{k}(P<0.05$ in all cases, except for $\alpha$ in week 5 , where $P=0.060$ ) than those from the HN tanks. Furthermore, both groups showed a distinct pattern of stability in photosynthetic performance until week 3, where after both experienced simultaneous decreases in $P_{\max }\left(F_{2.095,10.47}=15.49, P=0.0007\right.$ for $\mathrm{LN} ; F_{2.635,13.18}=$ $10.28, P=0.0012$ for $\mathrm{HN}), E_{k}\left(F_{2.014,10.07}=12.92, P=0.0016\right.$
Table 2 Pearson's correlation coefficients and their significance for each relationship between the photosynthetic variables and sterolic compounds of the low-nutrient and high-nutrient groups $(n=34$ except for LN cholesterol, where $n=33)$. Non-significant results $(P>0.05)$ are denoted by "ns". 24-methylenecholesterol and the unknown $\Delta^{5}$-sterol are abbreviated to "24-Met chol" and " $\Delta^{5}$-sterol" respectively; $P_{\max }, \alpha$, and $E_{k}$ denote maximum photosynthetic performance, light utilization efficiency, and saturating irradiance respectively

Photosynthetic variable Squalene (I) Cholesterol (II) Desmosterol (III) $\Delta^{5}$-sterol (U.S) 24 -Met chol (IV) Fucosterol (V) Cycloartenol (VI)

\begin{tabular}{|c|c|c|c|c|c|c|c|c|}
\hline \multicolumn{9}{|c|}{ Low nutrients } \\
\hline \multirow[t]{2}{*}{$P_{\max }$} & $r$ & -0.6312 & -0.3000 & 0.7357 & 0.8723 & -0.7475 & -0.6094 & 0.2472 \\
\hline & $P$ & $<0.0001$ & ns & $<0.0001$ & $<0.0001$ & $<0.0001$ & $<0.0001$ & ns \\
\hline \multirow[t]{2}{*}{$\alpha$} & $r$ & -0.7222 & -0.1336 & 0.5992 & 0.6195 & -0.5357 & 0.5804 & 0.1631 \\
\hline & $P$ & $<0.0001$ & ns & 0.0002 & $<0.0001$ & 0.0011 & 0.0003 & ns \\
\hline \multirow[t]{2}{*}{$E_{k}$} & $r$ & -0.5698 & 0.3024 & 0.7106 & 0.8469 & -0.7278 & -0.5702 & 0.2372 \\
\hline & $P$ & 0.0004 & ns & $<0.0001$ & $<0.0001$ & $<0.0001$ & 0.0004 & ns \\
\hline \multicolumn{9}{|c|}{ High nutrients } \\
\hline \multirow[t]{2}{*}{$P_{\max }$} & $\mathrm{r}$ & -0.6058 & 0.0392 & 0.4350 & 0.6771 & -0.7118 & -0.6112 & 0.0497 \\
\hline & $P$ & 0.0001 & ns & 0.0101 & $<0.0001$ & $<0.0001$ & 0.0001 & ns \\
\hline \multirow[t]{2}{*}{$\alpha$} & $r$ & -0.5508 & -0.0108 & 0.3641 & 0.4756 & -0.5370 & -0.5148 & 0.1320 \\
\hline & $P$ & 0.0007 & ns & 0.0343 & 0.0044 & 0.0011 & 0.0018 & ns \\
\hline \multirow[t]{2}{*}{$E_{k}$} & $r$ & -0.5774 & 0.0437 & 0.4155 & 0.6631 & -0.6943 & -0.5881 & 0.0375 \\
\hline & $P$ & 0.0003 & ns & 0.0145 & $<0.0001$ & $<0.0001$ & 0.0003 & ns \\
\hline
\end{tabular}



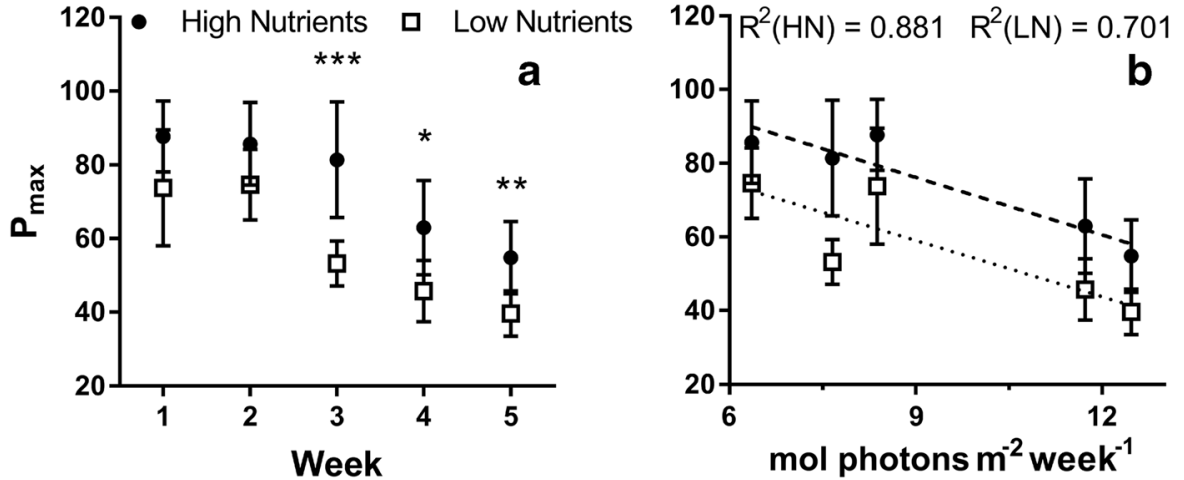

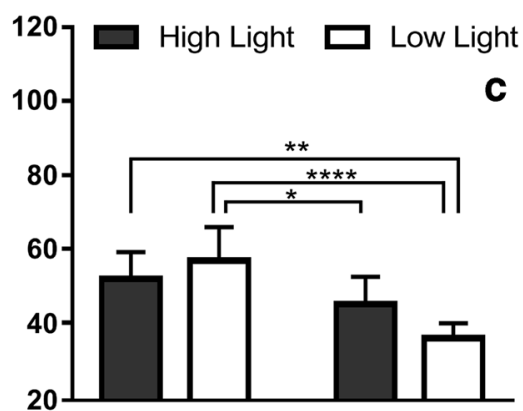

High Nutrients Low Nutrients
Fig. 5 Maximum photosynthetic performance $\left(P_{\max }\right)$ of the $\mathrm{LN}$ and $\mathrm{HN}$ groups during the nutrient variable cultivation experiment (weeks 1-5, outside cultivation tanks) plotted over time (a) and against the cumulative weekly irradiance (b), as well as during the nutrient and irradiance

for $\mathrm{LN} ; F_{2.7,13.5}=10.16, P=0.0011$ for $\mathrm{HN}$ ), and in $\alpha$ $\left(F_{2.101,10.5}=12.99, P=0.0013\right.$ for $\mathrm{LN} ; F_{1.875,9.377}=4.664$, $P=0.0409$ for $\mathrm{HN})$. These patterns were correlated with the weekly cumulative irradiance (Fig. 5; Fig. S3).

\section{Factorial effects of light and nutrient availability on S. latissima: sterols and photosynthesis}

Two-way ANOVAs rejected $\mathrm{H}_{0}$ and revealed significant interaction between the effects of light intensity and nutrient availability (week 6) on the concentration of all sterolic compounds of S. latissima $(P<0.05$ for all compounds; Table S4). variable experiment (week 6, climate-controlled cultivation; c). Data are presented as mean \pm S.D. ( $n=7$ except $\mathrm{HN}$ and $\mathrm{LN}$ week 5 and $\mathrm{HN}$, high light in week 6 , where $n=6$ ) and are accompanied by statistical significance: $* P<0.05 ; * * P<0.01 ; * * * P<0.001 ; * * * * P<0.0001$

As illustrated in Fig. 6 (numerical data in Table S5), the sterol content of $S$. latissima converged under low light conditions and diverged under high light conditions. Regardless of light intensity however, the sterol content of the LN group was significantly higher than that of the $\mathrm{HN}$ group $(P<0.05$ for all components except for squalene (I), cholesterol (II), and desmosterol (III) under low light conditions). A bidirectional response to light stress was observed for all sterol compounds, depending on nutrient treatment. For the high-nutrient group, the concentrations of fucosterol $(\mathbf{V})(P<0.05)$ and the unknown $\Delta^{5}$-sterol (U.S) $(P<0.0001)$ were significantly lower in $S$. latissima exposed to high light stress compared with

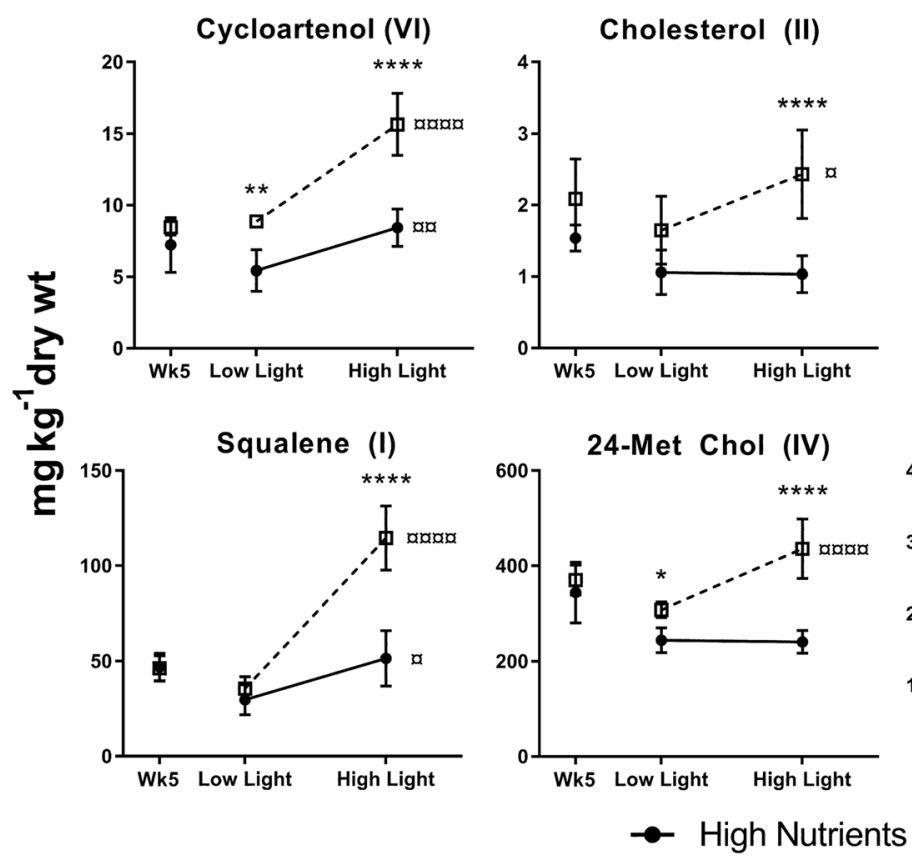

Fig. 6 Concentrations of the sterolic components in the high- and lownutrient groups exposed to high and low light conditions (week 6, climate controlled cultivation) with week 5 (Wk5) added as reference point. 24methylenecholesterol is abbreviated to "24-Met Chol." Data are given as mean \pm S.D. $(n=7)$ and accompanied by statistical significance:
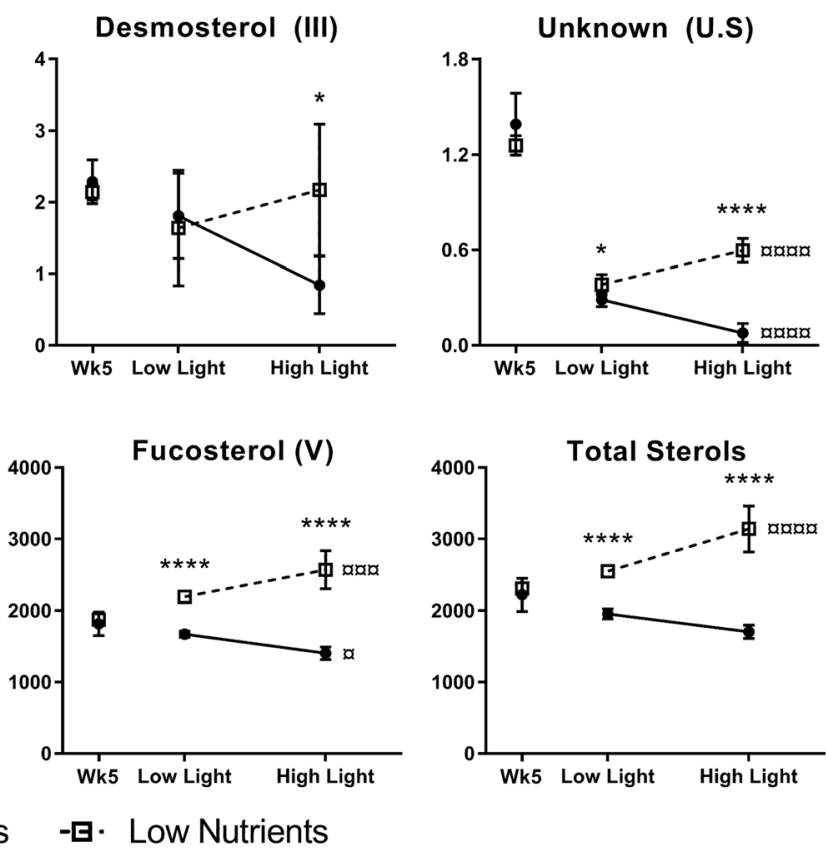

significant difference $* P<0.05 ; * * P<0.01 ; * * * P<0.001$; $* * * * P<0.0001$ between the high- and low-nutrient groups within a single light category. $\mathrm{x} P<0.05,000<<0.01 ; 00000<0.001 ; 000000<P 0.0001$ between the high- and low-light groups within a single nutrient group. Note the differences in scales 
S. latissima exposed to low light stress, while cholesterol (II), desmosterol (III), and 24-methylenecholesterol (IV) remained unchanged. For the low-nutrient group, the concentrations of all sterol compounds $(P<0.05)$ except for desmosterol (III) were significantly higher in S. latissima exposed to high light stress rather than low light stress. This bidirectional response did not hold true for the biosynthetic precursors squalene (I) and cycloartenol (VI), which showed a significant increase in concentration $(P<0.05$ in all cases) in the high-light stress individuals compared with the low light stress individuals, regardless of nutrient treatment.

A similar interaction was found between the effects of nutrient availability and light intensity on the photosynthetic measurements. A two-way ANOVA revealed significant interactions between irradiance and nutrient availability for $P_{\max }$ $\left(F_{1,23}=6.53 P<0.05\right)$ and $E_{k}\left(F_{1,23}=6.90, P<0.05\right)$ but not for $\alpha$, where the source of variation was light $\left(F_{1,23}=23.8\right.$, $P<0.0001)$. Herein, both the LN and HN groups exhibited significantly higher $\alpha$ under light-limiting irradiances $(P<0.05$ for $\mathrm{HN} ; P<0.01$ for $\mathrm{LN})$. The $\mathrm{LN}$ group showed a significant decrease in $E_{k}(P<0.01)$ under high-light stress, while light treatment had no significant effect on $E_{k}$ in the $\mathrm{HN}$ group. Neither groups showed significant differences in $P_{\max }$ depending on light treatment.

\section{Discussion}

\section{Sterols of Saccharina latissima}

Seaweed phytosterols are high-value compounds associated with potential health benefits, affording them and the seaweeds that produce them commercial interest. However, because little is known about how their production is affected by the cultivation environment, the efficiency with which these compounds can be exploited is limited. For this reason, we investigated the effects of nutrient availability and light stress on the sterol content of $S$. latissima in a pilot study. Our findings on the sterol content of $S$. latissima agree in part with the literature. The composition of sterols in this species has previously been reported to be $0.05 \%$ cholesterol (II), $11 \% 24$ methylenecholesterol (IV), $87 \%$ fucosterol (V), $0.05 \% 24$ ketocholesterol, and 1.8\% saringosterol (24-hydroxy-24vinylcholesterol) (Safe et al. 1974). We did not encounter any 24-ketocholesterol nor saringosterol in our samples, which may reflect a difference in post-harvest handling; these two compounds are often referred to as autoxidation products of fucosterol (V) (Knights 1970; Smith 1981), formed during the air-exposed handling and drying procedures common at that time (Smith 1981). Additionally, we detected desmosterol (III) in the sterol fraction of S. latissima, which was not observed by Safe et al. (1974). Desmosterol (III) is thought to be a precursor of fucosterol (V) (Patterson 1968; Goad et al.
1974) and has been observed in numerous Phaeophyceae (e.g., Aknin et al. 1992; Lopes et al. 2011), including those of the genus Laminaria (Patterson, 1968). Conversely, desmosterol is also thought to be a precursor of cholesterol in algal sterol biosynthesis, based on observations that demethylation at $\mathrm{C} 4$ and $\mathrm{C} 14$ takes place after $\mathrm{C} 24$ alkylation (Newburger et al. 1979). The unknown $\Delta^{5}$-sterol (U.S) shared a near-identical mass spectrum (supplement, Fig. S2) to brassicasterol, with the exception that we observed a peak at $\mathrm{m} / \mathrm{z} 253$, whereas all published mass spectra of brassicasterol show a peak at $\mathrm{m} / \mathrm{z} 255$, one notable exception being Kohlhase and Pohl (1988), who do report the m/z 253 peak. The elution order of the unknown sterol relative to cholesterol and 24-methylenecholesterol matches that of brassicasterol on a column with similar polarity (Patterson 1971). Lacking an authentic reference standard for brassicasterol, the unknown (U.S) is therefore only tentatively identified as such. Noteworthy is the presence of both squalene (I) and cycloartenol (VI), two integral intermediates in the biosynthesis of phytosterols, in the saponified extract of S. latissima. Both of these compounds were previously identified in Fucus spiralis (Goad and Goodwin 1969), and squalene (I) alone has been detected in Hormophysa cuneiformis (Hattab et al. 2007). To the best of our knowledge however, these two components have not previously been quantified in brown seaweeds.

\section{Effect of nutrient availability on S. latissima: sterols and photosynthesis}

Five weeks of nutrient-variable cultivation produced no significant differences in the concentration nor the composition of the sterolic components between the $\mathrm{LN}$ and $\mathrm{HN}$ groups with the exception of cycloartenol. This compound is the first cyclization product of squalene (I) in the biosynthetic pathway toward phytosterols (Desmond and Gribaldo 2009), and as such, increases in the concentration of cycloartenol (VI) but not in end products (e.g., fucosterol (V)) may indicate a reduced conversion of cycloartenol (VI) to sterols. That we did not observe any significant difference in the phytosterol content of the $\mathrm{LN}$ and $\mathrm{HN}$ groups is in agreement with Cronin and Hay (1996) who found that for neither D. ciliolata nor S. filependula did nutrient availability affect the sterol concentration. S. latissima is known to sequester inorganic nitrogen and phosphorus in excess of its metabolic requirements to build up internal nutrient reserves, which can subsequently be consumed in times of scarcity (Conolly and Drew 1985). It was recently shown that for young sporophytes of S. latissima, it can take 7 weeks for the internal nutrient pools to deplete under nutrient-limiting conditions (Lubsch and Timmermans 2019). Accordingly, the lack of significant differences in sterol content between the LN and HN groups may simply be the result of the $\mathrm{LN}$ group depleting their internal 
nitrogen and phosphorus reserves to compensate for the otherwise limited nutrient availability in the cultivation medium. Still, treatment-dependent differences were observed in photosynthetic performance, signifying that nutrient availability did affect the biochemistry of $S$. latissima within the experimental timeframe. The simultaneous decrease of $P_{\max }$ and $\alpha$ of $\mathrm{LN}$ individuals relative to $\mathrm{HN}$ individuals is indicative of a decrease in the number of photosynthetic units (PSUs) per cell (Richardson et al. 1983), the most probable cause of which is nitrogen limitation (Turpin 1991). The responses in sterol content and photosynthesis to nutrient availability are contrast with each other and may be an indication of a greater necessity to maintain sterol homeostasis, a greater sensitivity of photosynthetic performance toward nutrient availability or a combination thereof.

The lack of inter-treatment differences in sterol content is contrasted with the distinct temporal patterns in sterol content. The inter-weekly concentrations of squalene (I), desmosterol (III), 24-methylenecholesterol (IV), fucosterol (V), and the unknown $\Delta^{5}$-sterol (U.S) of both the $\mathrm{LN}$ and $\mathrm{HN}$ groups varied significantly and correlated with the photosynthetic performance. A similar, albeit stronger correlation has been described for Ulva rigida, wherein the sterol content was found to be inversely related to the functionality of the photosynthetic electron transport system (Gordillo et al. 2001). A possible explanation for this can be found in the microalga $N$. oceanica for which light appears to have a regulatory role in sterol biosynthesis. In this species, all examined genes involved in sterol biosynthesis were downregulated at high light stress, while the concentration of some minor sterols increased under those conditions (Lu et al. 2014). This divergent response of bulk and minor sterols is concurrent with our results, as we observed a negative correlation between the photosynthetic variables and fucosterol (V), its precursor 24-methylenecholesterol (IV), and the sterol precursor squalene (I), while a positive correlation was found for desmosterol (III) and the unknown $\Delta^{5}$-sterol (U.S), both of which are minor sterols. However, there are differences in metabolic rates and growth rates between micro- and macroalgae (Hein et al. 1995), and observations on sterol metabolism in microalgae may not necessarily translate to sterol metabolism in macroalgae.

\section{Factorial effects of light and nutrient availability on S. latissima: sterols and photosynthesis}

There was significant interaction between the effects of light stress and nutrient availability on the sterolic compounds of S. latissima. Previously, Cronin and Hay (1996) observed no interactive effect of light and nutrient availability on the sterol content of $D$. ciliolata nor S. filipendula. This discrepancy may be attributable to the fact that our light conditions reached stressful intensities in both our high and low light intensity groups. Cronin and Hay exposed D. ciliolata and
S. filipendula to only 19 and $72 \%$ of ambient surface irradiance, which may not have induced stress responses. Interestingly, the sterol content of the LN group was significantly higher than that of the $\mathrm{HN}$ group regardless of light intensity. Why this effect did not manifest during the nutrient variable cultivation period (week $1-5$ ) is not clear. It may be that during week 6 of cultivation, the nutrient reserves of the LN group were substantially depleted, or that the stressful light conditions caused a divergence of internal nutrient flux toward a metabolic system that does not maintain sterol homeostasis. Future research is necessary to elucidate the mechanisms behind the sudden relative differences in sterol content of the LN and HN groups.

There was a prominent difference between sterol concentrations of $S$. latissima individuals in the low- and highnutrient groups in response to light intensity. All sterolic compounds of the LN group except desmosterol (III) were significantly elevated under high light conditions, whereas these are unaffected or significantly reduced in concentration under the same conditions in the HN group. Herein, the HN group exhibited a response similar to the one described for $N$. oceanica (Lu et al. 2014), wherein high light stress resulted in downregulation of sterol biosynthetic genes and subsequently in bulk sterol concentration. However, the sterol concentrations of the LN group moved in opposite direction in response to high light stress. The sterol content of macroalgae has been observed to either increase or decrease in response to the same nutrient limitation dependent on the $\mathrm{CO}_{2}$ concentration (Gordillo et al. 2001). This suggests that a bidirectional response of macroalgal sterol content to the same abiotic factor can occur under factorial conditions.

This bidirectional response was observed in the photosynthetic variables as well. Both the LN and HN groups exhibited significantly higher $\alpha$ under light-limiting irradiances, which is a known acclimation mechanism of $S$. latissima (Machalek et al. 1996). However, whereas the HN group showed no significant differences in $P_{\max }$ nor $E_{k}$ depending on light treatment, the LN group showed a significant decrease in $E_{k}$. This suggests that the HN group was able to acclimatize to the low irradiance by simply increasing the size of their PSUs, whereas the LN group increased the size of their PSUs at the cost of photosynthetic enzyme activity or the number of PSUs per cell (Richardson et al. 1983; Falkowski and LaRoche 1991). The response of the LN group to low light stress indicates that the low nutrient treatment can be considered stressful relative to the high-nutrient treatment. Extrapolating this to the response in sterol concentration of the high- and low-nutrient groups to light stress suggests that a reduction in sterol concentration is the common response of S. latissima to high light stress. The increase in sterol concentration in response to high light stress as observed in the low-nutrient group would subsequently be an aberrant response, although the mechanism behind these observations remains unknown. 


\section{Conclusion}

We have shown that within the scope of our nutrient variable culture conditions, the sterol content of S. latissima changes with relative proportion to its photosynthetic function, but not with nutrient availability itself. During this period, we observed a $59 \%$ increase in the total sterol content of S. latissima that was concomitant with a decrease in photosynthetic performance. The highest total concentration of sterols was measured when the low-nutrient group was exposed to high light conditions. The observed total sterol content of $3141 \pm 322 \mathrm{mg} \mathrm{kg}^{-1}$ dry weight represents a $101 \%$ increase when compared with the sterol content of the same nutrient group at the start of the nutrient variable experiment $\left(1564 \pm 127 \mathrm{mg} \mathrm{kg}^{-1}\right.$ dry weight). Whether or not our results translate to $S$. latissima populations from commercial farms is conjecture, and this hypothesis will need to be tested under those field conditions before it can be accepted or rejected. Still, such a substantial increase would be of great interest for the valorization of S. latissima if it could be replicated in the field, as postponing the harvest period of S. latissima from May to a later period of summer would result in a harvest period characterized by decreased nutrient concentrations and increased light intensity relative to the preceding months.

Supplementary Information The online version contains supplementary material available at https://doi.org/10.1007/s10811-020-02359-y.

Acknowledgments We thank NIOZ colleagues Jeroen van Dalen for his assistance in constructing the light-variable cultivation setup, Alexander Ebbing for his advice on the cultivation parameters, Jacco Kromkamp for sharing his expertise in photosynthetic measurements, Jan Peene for measuring the nutrient concentrations, Louis Peperzak for his guidance in the statistical analysis of the data, and Stefan Schouten and Marianne Baas for their advice and expertise in the extraction and analyses of sterols. We also thank HZ University of Applied Sciences colleagues Tanja Moerdijk for her analytical insight during the sterol analyses and Sandra de Reu for her technical expertise and troubleshooting. In addition, we thank the anonymous reviewer for the constructive input.

Author contribution Dylan L.C. de Jong: conceptualization, methodology, investigation, data curation, formal analysis, visualization, writingoriginal draft, writing - review and editing, project management. Klaas R. Timmermans: conceptualization, methodology, resources, writingreview and editing, supervision. Jose M. de Winter: conceptualization, writing - review and editing, supervision. Goverdina C.H. Derksen: conceptualization, resources, writing - review and editing, supervision, funding acquisition.

Funding Funding was partially provided by the Toeslag voor Topconsortia voor Kennis en Innovatie (TKI's) of the Ministry of Economic Affairs, TKI Biobased Economy.

Data availability Data will be made available upon request.

\section{Compliance with ethical standards}

Competing interests The authors declare that they have no competing interests.
Open Access This article is licensed under a Creative Commons Attribution 4.0 International License, which permits use, sharing, adaptation, distribution and reproduction in any medium or format, as long as you give appropriate credit to the original author(s) and the source, provide a link to the Creative Commons licence, and indicate if changes were made. The images or other third party material in this article are included in the article's Creative Commons licence, unless indicated otherwise in a credit line to the material. If material is not included in the article's Creative Commons licence and your intended use is not permitted by statutory regulation or exceeds the permitted use, you will need to obtain permission directly from the copyright holder. To view a copy of this licence, visit http://creativecommons.org/licenses/by/4.0/.

\section{References}

Akihisa T, Kokke W, Tamura T (1992) Naturally occurring sterols and related compounds from plants. In: Patterson GW, Nes WD (eds) Physiology and biochemistry of sterols. American Oil Chemists' Society, Illinois, pp 172-228

Aknin M, Dogbevi K, Samb A, Kornprobst JM, Gaydou EM, Miralles J (1992) Fatty acid and sterol compositions of eight brown algae from the Senegalese coast. Comp Biochem Physiol 102B:841-843

Anding C, Brandt RD, Ourisson G (1971) Sterol biosynthesis in Euglena gracilis Z. Sterol precursors in light-grown and dark-grown Euglena gracilis Z. Eur J Biochem 24:259-263

Beardall J, Raven JA (2012) Algal metabolism. eLS:1-8

Black W (1954) Concentration gradients and their significance in Laminaria saccharina (L.) Lamour. J Mar Biol Assoc UK 33:49-60

Boderskov T, Schmedes PS, Bruhn A, Rasmussen MB, Nielsen MM, Pedersen MF (2016) The effect of light and nutrient availability on growth, nitrogen and pigment contents of Saccharina latissima (Phaeophyceae) grown in outdoor tanks, under natural variation of sunlight and temperature, during autumn and early winter in Denmark. J Appl Phycol 28:1153-1165

Bogie J, Hoeks C, Schepers M, Tiane A, Cuypers A, Leijten F, Chintapakorn Y, Suttiyut T, Pornpakakul S, Struik D, Kerksiek A, Liu HB, Martinez-Martinez P, Jonker JW, Dewachter I, Sijbrands E, Walter J, Hendriks J, Groen A, Staels B, Lütjohann D, Vanmierlo T, Mulder M (2019) Dietary Sargassum fusiforme improves memory and reduces amyloid plaque load in an Alzheimer's disease mouse model. Sci Rep 9

Brandt RD, Benveniste P (1972) Isolation and identification of sterols from subcellular fractions of bean leaves (Phaseolus vulgaris). Biochim Biophys Acta 282:85-92

Brandt RD, Pryce RJ, Anding C, Ourisson G (1970) Sterol biosynthesis in Euglena gracilis Z. Comparative study of free and bound sterols in light and dark grown Euglena gracilis Z. Eur J Biochem 17:344349

Breton TS, Nettleton JC, O’Connell B, Bertocci M (2018) Fine-scale population genetic structure of sugar kelp, Saccharina latissima (Laminariales, Phaeophyceae), in eastern Maine, USA. Phycologia 57:32-40

Camia A, Robert N, Jonsson R, Pilli R, Carcía-Condado S, LópezLozano R, van der Velde M, Ronzon T, Gurría P, M'Barek R, Tamosiunas S, Fiore G, Araujo R, Hoepffner N, Marelli L, Giuntoli J (2018) Biomass production, supply, uses and flows in the European Union. First results from an integrated assessment. Publications Office of the European Union, Luxembourg

Carlson RM, Tarchini C, Djerassi C (1980) Biological implications of recent discoveries in the marine sterol field. In: Ananchenko S (ed) Frontiers of bioorganic chemistry and molecular biology. Pergamon Press Ltd, Exeter, pp 211-224 
Conolly NJ, Drew EA (1985) Physiology of Laminaria: IV. Nutrient supply and daylengts, major factors affecting growth of $L$. digitata and L. saccharina. Mar Ecol 6:299-320

Cottenie K, de Meester L (2003) Comment to Oksanen (2001): reconciling Oksanen (2001) and Hurlbert (1984). Oikos 100:394-396

Cronin G, Hay ME (1996) Effects of light and nutrient availability on the growth, secondary chemistry and resistance to herbivory of two brown seaweeds. Oikos 77:93-106

Davison I, Reed RH (1985) Osmotic adjustment in Laminaria digitata (Phaeophyta) with particular reference to seasonal changes in internal solute concentrations. J Phycol 21:41-50

Davison I, Greene R, Podola E (1991) Temperature acclimation of respiration and photosynthesis in the brown alga Laminaria saccharina. Mar Biol 110:449-454

Desmond E, Gribaldo S (2009) Phylogenomics of sterol synthesis: insights into the origin, evolution, and diversity of a key eukaryotic feature. Genome Biol Evol 1:364-381

Dufourc EJ (2008) The role of phytosterols in plant adaptation to temperature. Plant Signal Behav 3:133-134

Falkowski PG, LaRoche J (1991) Acclimation to spectral irradiance in algae. J Phycol 27:8-14

FAO (2018) The global status of seaweed production, trade and utilization. FAO, Rome

Francavilla M, Trotta P, Luque R (2010) Phytosterols from Dunaliella tertiolecta and Dunaliella salina: a potentially novel industrial application. Bioresour Technol 101:4144-4150

Goad LJ, Akihisa T (1997) Analysis of sterols. Blackie Academic \& Professional, Cornwall

Goad LJ, Goodwin TW (1969) Studies in phytosterol biosynthesis: observations on the biosynthesis of fucosterol in the marine brown alga Fucus spiralis. Eur J Biochem 7:502-508

Goad LJ, Lenton JR, Knapp FF, Goodwin TW (1974) Phytosterol side chain biosynthesis. Lipids 9:582-595

Gordillo FJ, Goutx M, Figueroa FL, Niell FX (1998) Effects of light intensity, $\mathrm{CO}_{2}$ and nitrogen supply on lipid class compostiion of Dunaliella viridis. J Appl Phycol 10:135-144

Gordillo FJ, Jiménez C, Goutx M, Niell X (2001) Effects of CO2 and nitrogen supply on the biochemical composition of Ulva rigida with especial emphasis on lipid class analysis. J Plant Physiol 158:367373

Guschina IA, Harwood JL (2009) Algal lipids and effect of the environment on their biochemistry. In: Arts MT, Brett MT, Kainz MJ (eds) Lipids in aquatic ecosystems. Springer, New York, pp 1-24

Hartmann MA (1998) Plant sterols and the membrane environment. Trends Plant Sci 3:170-175

Hattab ME, Easa HS, Taberiès A, Piovetti L, Kornprobst JM (2007) Volatile components of the Phaeophyceae Hormophysa cuneiformis growing along Qatar coasts. J Essent Oil Res 19:37-39

Hein M, Pedersen MF, Sand-Jensen K (1995) Size-dependent nitrogen uptake in micro- and macroalgae. Mar Ecol Prog Ser 118:247-253

Juneja A, Ceballos RM, Murthy GS (2013) Effects of environmental factors and nutrient availability on the biochemical composition of algae for biofuels production: a review. Energies 6:4607-4638

Jung HA, Jung HJ, Jeong HY, Kwon JH, Kim MS, Choi JS (2014) Antiadipogenic activity of the edible brown alga Ecklonia stolonifera and its constituent fucosterol in 3T3-L1 adipocytes. Arch Pharm Res 37:713-720

Kamsma M (2017) De Noordzeeboerderij oogst wier. https://www.nrc.nl/ nieuws/2017/05/04/akkerbouw-op-volle-zee-8630323-a1557085. Accessed 16 Nov 2020

Kavita K, Singh VK, Jha B (2014) 24-branched $\Delta 5$ sterols from Laurencia papillosa red seaweed with antibacterial activity against human pathogenic bacteria. Microbiol Res 169:301-306

Knights B (1970) Sterols in Ascophyllum nodosum. Phytochemistry 9: 903-905
Kohlhase M, Pohl P (1988) Saturated and unsaturated sterols of nitrogenfixing blue-green algae (Cyanobacteria). Phytochemistry 27:17351740

Krauss RW, McAleer WJ (1953) Growth and evaluation of species of algae with regard to sterol content. In: Berlew JS (ed) Algal culture: from laboratory to pilot plant. Carnegie Institution of Washington, Washington, D.C., pp 316-325

Ktari L, Guyot M (1999) A cytotoxic oxysterol from the marine alga Padina pavonica (L.) Thivy. J Appl Phycol 11:511-513

Ktari L, Blond A, Guyot M (2000) 16ß-Hydroxy-5 $\alpha$-cholestane-3,6dione, a novel cytotoxic oxysterol from the red alga Jania rubens. Bioorg Med Chem Lett 10:2563-2565

Kumari P, Kumar M, Reddy C, Jha B (2013) Algal lipids, fatty acids and sterols. In: Domíngues H (ed) Functional ingredients from algae for foods and nutraceuticals. Woodhead Publishing Limited, Cambridge, pp 87-134

Lee C, Park GH, Ahn ME, Kim BA, Park CI, Jang JH (2013) Protective effect of Codium fragile against UVB-induced pro-inflammatory and oxidative damages in $\mathrm{HaCat}$ cells and $\mathrm{BALB} / \mathrm{c}$ mice. Fitoterapia 86:54-63

Lee JH, Jung HA, Kang MJ, Choi JS, Kim GD (2017) Fucosterol, isolated from Ecklonia stolonifera, inhibits adipogenesis through modulation of FoxO1 pathway in 3T3-L1 adipocytes. J Pharm Pharmacol 69:325-333

Li GL, Guo WJ, Wang GB, Wang RR, Hou YX, Liu K, Liu Y, Wang W (2017) Sterols from the green alga Ulva australis. Mar Drugs 15:299

Lin AS, Engel S, Smith BA, Fairchild CR, Aalbersberg W, Hay ME, Kubanek J (2010) Structure and biological evaluation of novel cytotoxic sterol glycosides from the marine red alga Peyssonnelia sp. Bioorg Med Chem 18:8264-8269

Lopes G, Sousa C, João B, Andrade PB, Valentão P, Ferreres F, Mouga $T$ (2011) Sterol profiles in 18 macroalgae of the Portuguese coast. J Phycol 47:1210-1218

Lopes G, Sousa C, Valentão P, Andrade PB (2014) Sterols in algae and health. In: Hernández-Ledesma B, Herrero M (eds) Bioactive compounds from marine foods: plant and animal sources. Wiley, Sussex, pp 173-191

Lu Y, Zhou W, Wei L, Li J, Jia J, Li F, Smith SM, Xu J (2014) Regulation of the cholesterol biosynthetic pathway and its integration with fatty acid biosynthesis in the oleaginous microalga Nannochloropsis oceanica. Biotechnol Biofuels 7:81

Lubsch A, Timmermans KR (2019) Uptake kinetics and storage capacity of dissolved inorganic phosphorus and corresponding dissolved indorganic nitrate uptake in Saccharina latissima and Laminaria digitata (Phaeophyceae). J Phycol 55:637-650

Machalek K, Davidson I, Falkowski P (1996) Thermal acclimation and photoacclimation of photosynthesis in the brown alga Laminaria saccharina. Plant Cell Environ 19:1005-1016

Newburger JD, Uebel JJ, Ikawa M, Andersen KK, Gagosian RB (1979) Sterols of Agarum cribosum: Desmosterol in a brown alga. Phytochemistry 18:2042-2043

Parodi A, Leip A, de Boer IJM, Slegers PM, Ziegler F, Temme EHM, Herrero M, Tuomisto H, Valin H, van Middelaar CE, van Loon JJA, van Zanten HHE (2018) The potential of future foods for sustainable and healthy diets. Nat Sustain 1:782-789

Patterson GW (1968) Sterols of Laminaria. Comp Biochem Physiol 24: 501-505

Patterson GW (1971) Relation between structure and retention time of sterols in gas chromatography. Anal Chem 43:1165-1170

Peterson D (1951) Effect of soybean sterols in the diet on plasma and liver cholesterol in chicks. Exp Biol M 78:143-147

Piepho M, Martin-Cruezburg D, Wacker A (2010) Simultaneous effects of light intensity and phosphorus supply on the sterol content of phytoplankton. PLOS One 5:e15828 
Piepho M, Martin-Creuzburg D, Wacker A (2012) Phytoplankton sterol contents vary with temperature, phosphorus and silicate supply: a study on three freshwater species. Eur J Phycol 47:138-145

Richardson K, Beardall J, Raven J (1983) Adaptation of unicellar algae to irradiance: an analysis of strategies. New Phytol 93:157-191

Safe LM, Wong CJ, Chandler RF (1974) Sterols of marine algae. J Pharm Sci 63:464-466

Schmid M, Stengel D (2015) Intra-thallus differentiation of fatty acid and pigment profiles in some temperate Fucales and Laminariales. J Phycol 51:25-36

Sheu JH, Sung PJ (1991) Isolation of 24-hydroperoxy-24vinylcholesterol and fucosterol from the brown alga Turbinaria conoides. J Chin Chem Soc-Taip 38:501-503

Smith LL (1981) Distribution of autoxidation products. In: Cholesterol autoxidation. Plenum Press, New York, pp 49-123

Turpin DH (1991) Effects of inorganic N availability on algal photosynthesis and carbon metabolism. J Phycol 27:14-20

van den Burg SW, van Duijn AP, Bartelings H, van Krimpen MM, Poelman M (2016) The economic feasibility of seaweed production in the North Sea. Aquac Econ Manag 20:235-252

van den Burg S, Dagevos H, Helmes R (2019) Towards sustainable European seaweed value chains: a triple P perspective. ICES J Mar Sci:fsz183

van der Molen J, Ruardij P, Mooney K, Kerrison P, O'Conner NE, Gorman E, Timmermans K, Wright S, Kelly M, Hughes AD,
Capuzzo E (2018) Modelling potential production of macroalgae farms in UK and Dutch coastal waters. Biogeosciences 15:11231147

Vanmierlo T, Bogie JF, Mailleux J, Vanmol J, Lütjohann D, Mulder M, Hendriks JJ (2015) Plant sterols: Friend or foe in CNS disorders? Prog Lipid Res 58:26-39

Volkman J (2003) Sterols in microorganisms. Appl Microbiol Biotechnol 60:495-506

Wächter GA, Franzblau SG, Montenegro G, Hoffman JJ, Maiese WM, Timmermann BN (2001) Inhibition of Mycobacterium tuberculosis growth by saringosterol from Lessonia nigrescens. J Nat Prod 64: 1463-1464

Webb WL, Newton M, Starr D (1974) Carbon dioxide exchange of Alnus rubra: a mathematical model. Oecologia 17:281-291

Zaiontz C (2019) Real Statistics Resource Pack. http://www.realstatistics.com. Accessed 5 May 2019

Zhila N, Kalacheva G, Volova T (2005) Effect of nitrogen limitation on the growth and lipid composition of the green alga Botryococcus braunii Kütz IPPAS H-252. Russ J Plant Physiol 52:311-319

Publisher's note Springer Nature remains neutral with regard to jurisdictional claims in published maps and institutional affiliations. 